\title{
Inactivation of Salmonella Typhimurium and Escherichia coli 0157:H7 on black pepper powder using UV-C, UV-A and $\mathrm{TiO}_{2}$ coating
}

\author{
Mi-Jung Park ${ }^{1} \cdot$ Jin-Hee Kim ${ }^{1} \cdot$ Se-Wook Oh${ }^{1}$
}

Received: 26 March 2019/Revised: 28 May 2019/Accepted: 18 July 2019/Published online: 12 August 2019

(C) The Korean Society of Food Science and Technology 2019

\begin{abstract}
This study was conducted to measure the inactivation characteristics of UVs and $\mathrm{TiO}_{2}$ against Salmonella. Typhimurium and Escherichia coli $\mathrm{O} 157: \mathrm{H} 7$ on black pepper powder. The sample was irradiated by UV-A and UV-C combined with $\mathrm{TiO}_{2}$ coating. After treatment, microbial and physicochemical analysis was carried out. Among various sterilization conditions, the largest number of pathogen in black pepper powder was inactivated by UV-A and UV-C combined with $\mathrm{TiO}_{2}$ coating. The microbial count of black pepper powder treated simultaneously with UV-A and UV-C was less than that of black pepper powder treated with alone. The inactivation effect of UV-A and UV-C was increased when $\mathrm{TiO}_{2}$ coating was combined. Moisture content was decreased with increasing treatment time, but color did not change. In this study, it was indicated that the combined treatment of UV-C, UV-A and $\mathrm{TiO}_{2}$ coating was effective for reducing $S$. Typhimurium and E. coli $\mathrm{O} 157: \mathrm{H} 7$ on black pepper powder.
\end{abstract}

Keywords UV-C $\cdot$ UV-A $\cdot \mathrm{TiO}_{2}$ coating $\cdot$ Black pepper powder $\cdot$ Inactivation effect

Se-Wook Oh

swoh@kookmin.ac.kr

Mi-Jung Park

qlorvv@nate.com

Jin-Hee Kim

Jinhi325003@naver.com

1 Department of Food and Nutrition, Kookmin University, Seoul 02727, Republic of Korea

\section{Introduction}

In recent years, consumer's interest in natural flavor and taste has increased, and research on non-heat treatment technology to ensure food quality and safety has been actively conducted (Knorr et al., 2011; Ojha et al., 2015). Titanium dioxide $\left(\mathrm{TiO}_{2}\right)$ is a photocatalyst that is used to make an antimicrobial surface and has proved to be effective for sterilizing a wide range of microorganisms, including endospores (Foster et al., 2011). $\mathrm{TiO}_{2}$ does not produce byproducts, can be used repeatedly, and has the advantages of being stable and non-toxic under UV irradiation. (Yemmireddy and Hung, 2015). $\mathrm{TiO}_{2}$ has also been approved by the American Food and Drug Administration for use in human food, drugs, cosmetics, and food contact materials (Chawengkijwanich and Hayata, 2008). The mechanism of action of $\mathrm{TiO}_{2}$ is due to the production of reactive oxygen species(ROS) with strong oxidizing power when UV light is irradiated at wavelengths of less than $385 \mathrm{~nm}$ (Maness et al., 1999). When microorganisms are exposed to $\cdot \mathrm{O}_{2}$ and $\cdot \mathrm{OH}$ produced by photocatalyst, oxidative damage occurs in cell walls, cell membranes, DNA, and RNA (Blake et al., 1999). The oxidation of unsaturated phospholipids destroys the cell membrane, and the increase of ion permeability induces cell death by inducing oxidation of the internal cellular components (Alrousan et al., 2009).

Ultraviolet rays have a antimicrobial effect against many kinds of microorganisms including viruses (Guerrero Beltr.n and Barbosa C.novas, 2004) and are used to sterilize air, water, and surfaces of food or cooking utensils (Gayán et al., 2011). UV-C is a light with a wavelength of 200-270 nm, which is readily absorbed by DNA, leading to the production of a large amount of pyrimidine dimers. The pyrimidine dimers formed by the absorption of UV-C 
into DNA kills cells by interfering with DNA transfer and replication, making UV-C effective in sterilizing microorganisms. (Chevremont et al., 2012). UV-C does not create chemical residues, has low cost maintenance, and does not change quality because it is dry and cold processes (Guerrero-Beltr-n and Barbosa-C.novas, 2004). UV-A has a wavelength of 320-400 $\mathrm{nm}$ that induces the formation of active substances such as peroxide, which has a inactivation effect on the survival of microorganisms (Oppezzo and Pizarro, 2001). UV-A causes cell membrane damage due to long wavelengths, and shows lethal effects against microorganisms (Bintsis et al., 2000). Recent studies have shown that the antimicrobial effect of combined treatment with UV-C and UV-A is more effective than the effect of using UV-C or UV-A alone (Chevremont et al., 2012).

Black pepper is one of the most important and widely used spices in the world, and about 315,000-320,000 tons of the pepper are produced in 26 countries (Peter, 2006). However, Boer et al. found that black pepper showed a high level of microbial contamination above $10^{7} \mathrm{CFU} / \mathrm{g}$ (De Boer et al., 1985). Black pepper is used as a spice to enhance taste and aroma in various dishes. Therefore, if spices such as black pepper are contaminated with bacterial pathogens, pathogens can easily enter food and cause food poisoning (McKee, 1995). Salmonella Typhimurium and Escherichia coli $\mathrm{O} 157: \mathrm{H} 7$ are the most frequently reported pathogens causing food poisoning and life-threatening diseases (Tarr, 1995; Zweifel and Stephan, 2012).

Salmonella Typhimurium causes salmonellosis (Alley et al., 2002) and E. coli O157:H7 cause diarrhea and hemolytic uremic syndrome disease after infection (Besser et al., 1993). Animal manure is a common carrier of pathogens such as $S$. Typhimurium and E. coli $\mathrm{O} 157: \mathrm{H} 7$, and black pepper grown on the ground can be infected with pathogens due to animal manure (Islam et al., 2004). It was reported that the cause of a large-scale salmonella infection in the United States from July 2009 to April 2010 was contaminated pepper added to salami products (Julian et al., 2009).

The inactivation effects of $\mathrm{TiO}_{2}$ coating, UV-A, and UV-C against $S$. Typhimurium and E. coli $\mathrm{O} 157: \mathrm{H} 7$ on black pepper powder have not been previously reported. Therefore, this study proposed treatment combined with $\mathrm{TiO}_{2}$ coating, UV-A, and UV-C to inhibit $S$. Typhimurium and E. coli $\mathrm{O} 157: \mathrm{H} 7$ growth on black pepper powder without heating.

\section{Materials and methods}

\section{Bacterial strains of $S$. Typhimurium and $E$. coli 0157:H7}

Three strains of Salmonella Typhimurium (ATCC 6994, 14028, 19585) and three strains of Escherichia coli O157:H7 (ATCC 43894, 43895, 35150) were obtained from Korean Collection for Type Cultures. All strains were stored at $-80{ }^{\circ} \mathrm{C}$ in stock form. Stocks were prepared by mixing $0.5 \mathrm{~mL}$ of bacteria culture and $0.5 \mathrm{~mL}$ of $100 \%$ glycerol. The strains were cultured in tryptic soy broth (TSB; Difco Co., Franklin Lakes, NJ, USA) before use.

\section{Bacteria culture preparation}

Three strains of $S$. Typhimurium and three strains of $E$. coli O157:H7 were each added to $10 \mathrm{~mL}$ of TSB and incubated at $37{ }^{\circ} \mathrm{C}$ for $9 \mathrm{~h}$. After incubation, $0.1 \mathrm{~mL}$ of the culture broth was inoculated into $10 \mathrm{~mL}$ of another TSB and cultured at $37{ }^{\circ} \mathrm{C}$ for $18 \mathrm{~h}$ again. The culture broth was centrifuged at $9000 \times g$ for $20 \mathrm{~min}$ at $4{ }^{\circ} \mathrm{C}$, and the resulting pellet was resuspended in $5 \mathrm{~mL}$ of $0.85 \%$ saline $(8.5 \mathrm{~g} / \mathrm{L}$ sodium chloride; Sigma-Aldrich Corp., St. Louis, Mo., USA) (washing step). The washing step was repeated two more times. In the process, cocktails of bacterial cultures were performed between the same strains. Finally, the pellet was resuspended using $30 \mathrm{~mL}$ of $0.85 \%$ saline and used for experiment.

\section{Sample preparation and inoculation}

Black pepper powder (BPP) was obtained a bulk packaged in a pouch from local market and used for the experiment. The BPP was filtered with a 35-mesh sieve, and the size of the pepper powder was less than 35 mesh. The pepper powder of $150 \mathrm{~g}$ was placed in a sterile bag (Whirl-pak; $19.30 \mathrm{~cm}$, Nasco, Fort Atkinson, WI, USA), and was added $5 \mathrm{~mL}$ of the bacterial culture for inoculation. And then, BPP in the bag was massaged by hand for 2 min and was dried in a biosafety hood for $1 \mathrm{~h}$. Finally, about $10^{5}-10^{6}$ CFU/g of $S$. Typhimurium and E. coli $\mathrm{O} 157: \mathrm{H} 7$ was inoculated on BPP.

\section{System combined with UV-A, UV-C, and roaster- coated $\mathrm{TiO}_{2}$ and treatment}

All treatments were performed in a biosafety hood built-in air circulation system to prevent heat accumulation and microbial contamination. A roaster machine (MK-300, Miko Electrical Co., Ltd., Foshan, Guangdong PR, China), G40T10 Germicidal UV-C lamp $(253.7 \mathrm{~nm}, 40 \mathrm{~W}$, 
SANKYO DENKI Co., Ltd., Kanagawa, Japan), and F40T10 Blacklight UV-A lamp (352 nm, 40 W, SANKYO DENKI Co., Ltd.) were installed in the biosafety hood.

To make a $\mathrm{TiO}_{2}$ paste, $\mathrm{TiO}_{2}$ powder (Aeroxide ${ }^{\circledR} \mathrm{TiO} 2$ P25; $21 \mathrm{~nm}$, Defussa Co., Germany) of $5 \mathrm{~g}$ was added to $45 \mathrm{~mL}$ of polycrylic (MinWax ${ }^{\circledR}$ Water based polyacrylic; MinWax co., USA) and stirred for $1 \mathrm{~h}$. After stirring, the solution was sonicated for $1 \mathrm{~h} .5 \mathrm{~mL}$ of the prepared $\mathrm{TiO}_{2}$ paste was coated once on Glad plastic wrap (Glad Food Plastic Wrap, width $30 \mathrm{~cm}$, length $43.4 \mathrm{~cm}$, United States) using a brush, and the $\mathrm{TiO}_{-}$-coated plastic wrap was attached to top surface of the roaster machine for $\mathrm{TiO}_{2}$ coating treatment.

The BPP was treated by UV-A (length $119.8 \mathrm{~cm}$, lamp diameter $32 \mathrm{~mm}$ ) and UV-C (length $119.8 \mathrm{~cm}$, lamp diameter $32 \mathrm{~mm}$ ) on the roaster machine (diameter $24 \mathrm{~cm}$, depth $3.5 \mathrm{~cm}$ ). The samples were placed $6 \mathrm{~cm}$ away from the UV lamp and the roaster machine continuously mixed the samples. The wavelengths of the UV-A and the UV-C installed in the biosafety hood were 352 and $253.7 \mathrm{~nm}$, respectively, and the irradiation dose was $1.11 \mathrm{~W} / \mathrm{cm}^{2}$. UV-A and UV-C were treated alone or in combination for 0, 30, 60, 90, 120, 150, and $180 \mathrm{~min}$. Two UV lamps were used for each treatment. One UV-A lamp and one UV-C lamp were used when combining UV-A and UV-C.

\section{Microbial analysis and injured cell enumeration}

Treated BPP of $10 \mathrm{~g}$ and $90 \mathrm{~mL}$ of sterilized $0.85 \%$ saline put into a sterile bag and was homogenized for 2 min by a stomacher (Laboratory Blender Stomacher 400; Seward, MO, USA). The sample of $1 \mathrm{~mL}$ was serially diluted with $0.85 \%$ physiological saline, and then plated on each selective medium. To detect for $S$. Typhimurium and E. coli O157:H7, Xylose-Lysine-Deoxycholate agar (XLD agar; Difco, Becton-Dickinson Co., Sparks, MD) and Sorbitol MacConkey agar (SMac agar; Oxoid, Hampshire, UK) were used, respectively. The homogenized sample solution was incubated on selective agar at $37^{\circ} \mathrm{C}$ for 24-48 $\mathrm{h}$ and the colonies formed on the plates were counted.

The overlay (OV) method was used to measure the population of injured cells caused by UV-A, UV-C, and $\mathrm{TiO}_{2}$ coatings (Lee and Kang, 2001). Tryptone soya agar (TSA; Oxoid, Hampshire, UK) was used as a nutrient medium to recover injured $S$. Typhimurium and $E$. coli O157:H7. The diluted sample suspension was plated on TSA, and the plate was cultured at $37{ }^{\circ} \mathrm{C}$ for $2 \mathrm{~h}$. Then, 7$8 \mathrm{~mL}$ of XLD agar and SMac agar were poured on the plate (Kang and Siragusa, 1999). When the agar was hard, the plate was incubated at $37{ }^{\circ} \mathrm{C}$ for $24-48 \mathrm{~h}$, and then and the colonies formed were counted. The colony number was calculated by Ukuku in terms of \% population of injured cells via the following formula (Ukuku and Geveke, 2010):

[ 1 - colonies on selective agar/counts on agar in OV method] $\times 100$

\section{Moisture measurement and color measurement}

OHAUS MB 45 Moisture Analyzers (MB 45; OHAUS, NJ, USA) were used to measure the moisture content of BPP. Moisture content of BPP were measured at 0, 30, 60, 90, 120,150 , and $180 \mathrm{~min}$ during treatment. When each treatment was end, $2 \mathrm{~g}$ of BPP was put on an aluminum dish and was measured the moisture content by heating at $140{ }^{\circ} \mathrm{C}$ for $10 \mathrm{~min}$.

A colorimeter (CR-400 Chroma Meter; Konica Minolta Sensing, Inc., Japan) was used to determine the effect of UV-A, UV-C and $\mathrm{TiO}_{2}$ coatings on the color of BPP. To measure the color change of BPP, $L^{*}, a^{*}$ and $b^{*}$ values were measured using $2 \mathrm{~g}$ of BPP before and after treatment.

\section{Statistical analysis}

All experiments were repeated three times to calculate average number of microorganisms and results were converted to $\log \mathrm{CFU} / \mathrm{g}$. IBM SPSS statistics program (version 23, IBM Corp., USA) statistically performed the analysis of variance on calculated results. Duncan's multiple range test separated the mean values of results. This study concluded that there was a significant difference between the samples when $p$ was less than 0.05 .

\section{Results and discussion}

\section{Antimicrobial effect of $\mathrm{UV}-\mathrm{A}, \mathrm{UV}-\mathrm{C}$ and $\mathrm{TiO}_{2}$ coating on BPP}

The inactivation effect of UV-A, UV-C and $\mathrm{TiO}_{2}$ coating against $S$. Typhimurium on BPP is shown in Fig. 1. In Fig. 1(A) is a group treated without $\mathrm{TiO}_{2}$, and (B) is a group treated with $\mathrm{TiO}_{2}$. The initial concentration of $S$. Typhimurium on BPP was $5.42 \pm 0.11 \mathrm{log} \mathrm{CFU} / \mathrm{g}$.

UV-A alone (UA) and UV-C alone (UC) inhibited 1.04 and $0.93 \log \mathrm{CFU} / \mathrm{g}$ of $S$. Typhimurium, respectively. When UV-A and UV-C were applied in combination (UAC), $1.74 \log \mathrm{CFU} / \mathrm{g}$ of $S$. Typhimurium was inactivated. The combined treatment of $\mathrm{TiO}_{2}$ and UV-A (TUA) and the combined treatment of $\mathrm{TiO}_{2}$ and UV-C (TUC) reduced about 1.65 and $1.08 \log \mathrm{CFU} / g$ of $S$. Typhimurium, respectively. When $\mathrm{TiO}_{2}, \mathrm{UV}-\mathrm{A}$ and UV-C were 


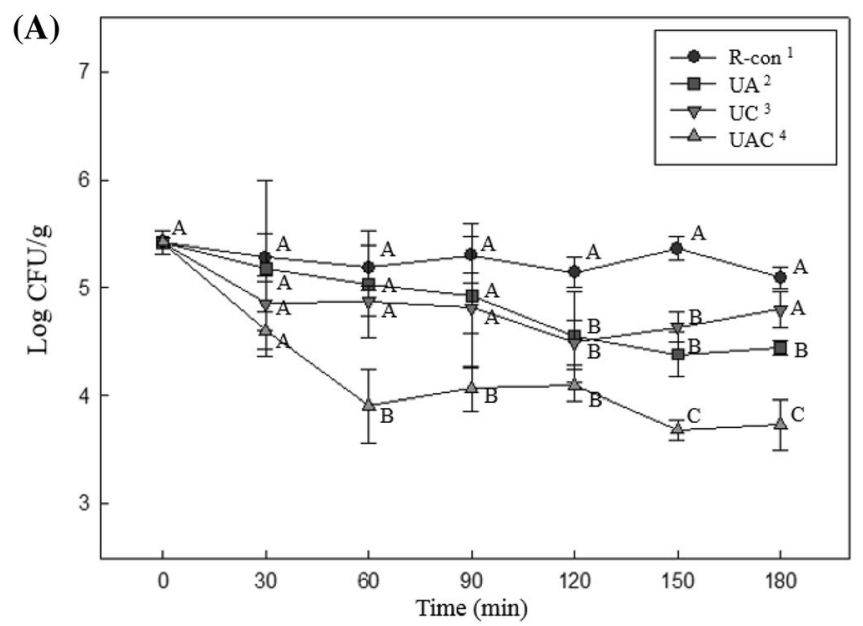

Fig. 1 Inactivation effect of UV-A, UV-C, and $\mathrm{TiO}_{2}$ coating against $S$. Typhimurium inoculated on black pepper powder for $0,30,60,90$, 120,150 , and $180 \mathrm{~min}$. Mean \pm standard deviation obtained in two experiments, one of two experiments in duplicated $(n=3)$. The treatment involving $\mathrm{TiO}_{2}$ coating is $(\mathbf{A})$, and the treatment excluding $\mathrm{TiO}_{2}$ coating is (B). Different capital letters indicate significant

treated together (TUAC) for $180 \mathrm{~min}, 2.17 \mathrm{log}$ CFU/g of $S$. Typhimurium was reduced. The inactivation effect of UA was significantly $(p<0.05)$ higher than that of UC when treated for $150 \mathrm{~min}$, and UAC was significantly $(p<0.05)$ higher than UA and UC after 60 min of treatment. When TUA or TUC was applied for more than $90 \mathrm{~min}, S$. Typhimurium on BPP was significantly $(p<0.05)$ different from the control group (R-con) that was treated using only a roaster machine. When TUAC was treated for $30 \mathrm{~min}$, the inactivation effect was significantly $(p<0.05)$ higher than that of TUA and TUC, and TUAC reduced most $S$. Typhimurium on BPP.

TUA showed a higher inactivation effect than UA against $S$. Typhimurium on BPP, and showed a significant $(p<0.05)$ difference between 90 and $180 \mathrm{~min}$. When treated for $30 \mathrm{~min}$, TUC reduced significantly $(p<0.05)$ more $S$. Typhimurium than UC, but there was no significant $(p>0.05)$ difference between the inactivation effects of the two treatments thereafter. Salmonella Typhimurium was significantly $(p<0.05)$ more inactivated on BPP treated by TUAC and UAC than R-con, and TUAC reduced significantly $(p<0.05)$ more $S$. Typhimurium than UAC after 150 min.

Salmonella Typhimurium was more inactivated by the treatment combined with UV-A and UV-C than treatment using UV-A and UV-C alone. In addition, $\mathrm{TiO}_{2}$ coatings significantly $(p<0.05)$ increased the inactivation effects of UV-A and UV-C against $S$. Typhimurium on BPP.

The inactivation effect of UV-A, UV-C, and $\mathrm{TiO}_{2}$ coating against $E$. coli $\mathrm{O} 157: \mathrm{H} 7$ on BPP is shown in Fig. 2. In Fig. 2(A) is a group treated without $\mathrm{TiO}_{2}$, and (B) is a

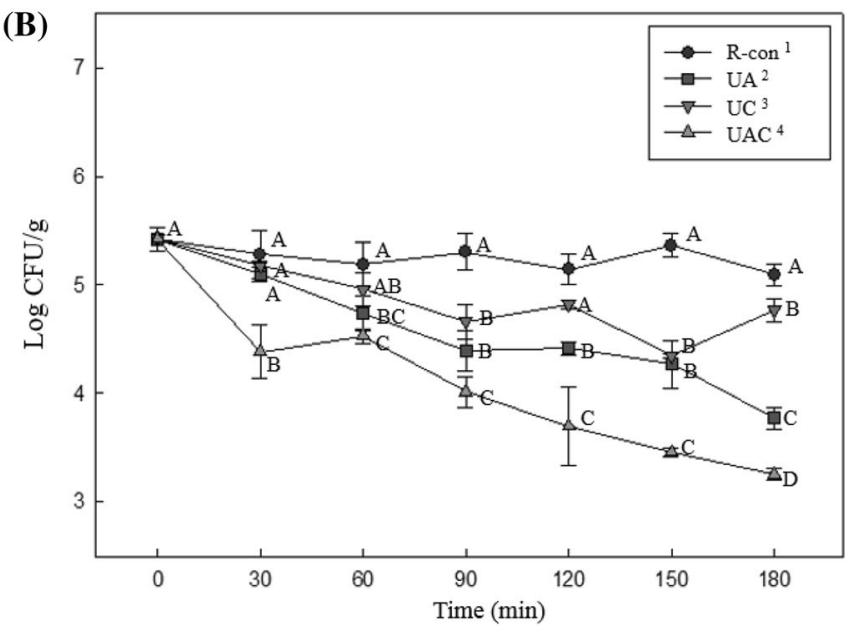

differences $(p<0.05)$ among treatments for each time. ${ }^{1} \mathrm{R}$-con means control group that was treated using only a roaster machine. ${ }^{2} \mathrm{UA}$ means a group that was treated by UV-A alone. ${ }^{3} \mathrm{UC}$ means a group that was treated by UV-C alone. ${ }^{4} \mathrm{UAC}$ means a group that was treated by UV-A and UV-C simultaneously

group treated with $\mathrm{TiO}_{2}$. The initial concentration of $E$. coli O157:H7 on BPP was $6.64 \pm 0.10 \log \mathrm{CFU} / \mathrm{g}$.

UA and UC inhibited E. coli $\mathrm{O} 157: \mathrm{H} 7$ by 1.13 and 1.54 $\log$ CFU/g, respectively. UAC inactivated $1.46 \log \mathrm{CFU} / \mathrm{g}$ of $E$. coli $\mathrm{O} 157: \mathrm{H} 7$ for $180 \mathrm{~min}$. For $180 \mathrm{~min}$, TUA and TUC reduced E. coli O157:H7 by 1.46 and $1.80 \log$ CFU/g, respectively. When TUAC was applied for $180 \mathrm{~min}$, E. coli O157:H7 on BPP was inactivated by $1.74 \log \mathrm{CFU} / \mathrm{g}$. TUA inhibited significantly $(p<0.05)$ more $E$. coli $\mathrm{O} 157: \mathrm{H} 7$ than UA for $120 \mathrm{~min}$. A number of $E$. coli $\mathrm{O} 157: \mathrm{H} 7$ was significantly $(p<0.05)$ reduced by UC and TUC compared with R-con, and E. coli $\mathrm{O} 157: \mathrm{H} 7$ was more inactivated by TUC than UC at $180 \mathrm{~min}$. There was no significant $(p>0.05)$ difference between R-con, UAC, and TUAC until $30 \mathrm{~min}$. However, TUAC showed a similar or significantly $(p<0.05)$ better inactivation effect than UCA after $60 \mathrm{~min}$.

UC showed a bactericidal effect against $E$. coli $\mathrm{O} 157: \mathrm{H} 7$ similar to that of TUC. The BPP treated by UAC had significantly $(p<0.05)$ fewer E. coli $\mathrm{O} 157: \mathrm{H} 7$ than the pepper powder of R-con, and TUAC inactivated significantly $(p<0.05)$ more E. coli $\mathrm{O} 157: \mathrm{H} 7$ than the R-con from 60 to $180 \mathrm{~min}$. The inactivation effect of UV-A and UV-C against E. coli $\mathrm{O} 157: \mathrm{H} 7$ was enhanced by the $\mathrm{TiO}_{2}$ coating.

The inactivation effect of UA, UC and UAC against $S$. Typhimurium was increased with $0.67,0.48$, and $0.03 \mathrm{log}$ $\mathrm{CFU} / \mathrm{g}$ for $180 \mathrm{~min}$ by $\mathrm{TiO}_{2}$ coating, respectively. The inactivation effect of UA, UC, and UAC against $E$. coli O157:H7 was increased with 0.33, 0.25, and $0.27 \log \mathrm{CFU} /$ $\mathrm{g}$, when also treated with $\mathrm{TiO}_{2}$ coating for $180 \mathrm{~min}$. According to the results, it was confirmed that the 


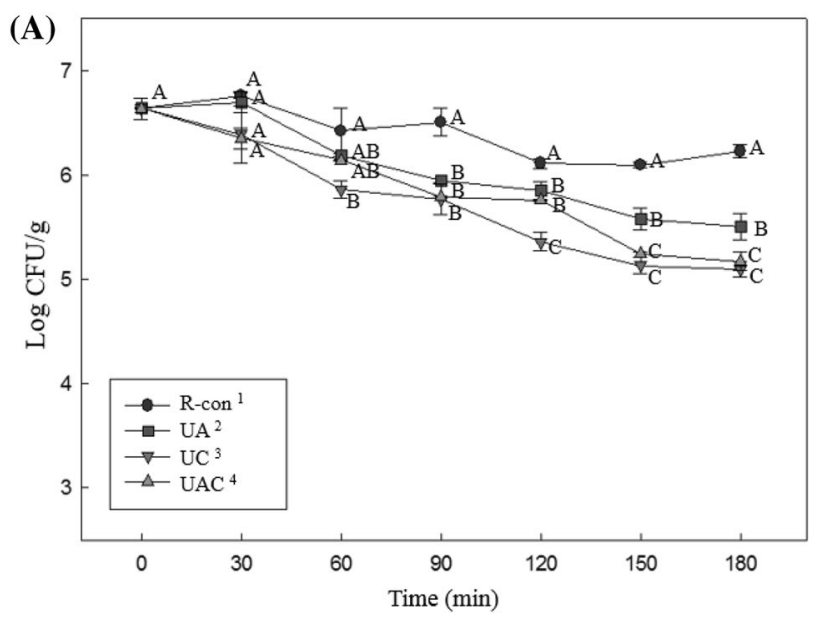

Fig. 2 Inactivation effect of UV-A, UV-C, and $\mathrm{TiO}_{2}$ coating against E. coli $\mathrm{O} 157: \mathrm{H} 7$ inoculated on black pepper powder for 0, 30, 60, 90, 120,150 , and $180 \mathrm{~min}$. Mean \pm standard deviation obtained in two experiments, one of two experiments in duplicated $(n=3)$. The treatment involving $\mathrm{TiO}_{2}$ coating is $(\mathbf{A})$, and the treatment excluding $\mathrm{TiO}_{2}$ coating is (B). Different capital letters indicate significant

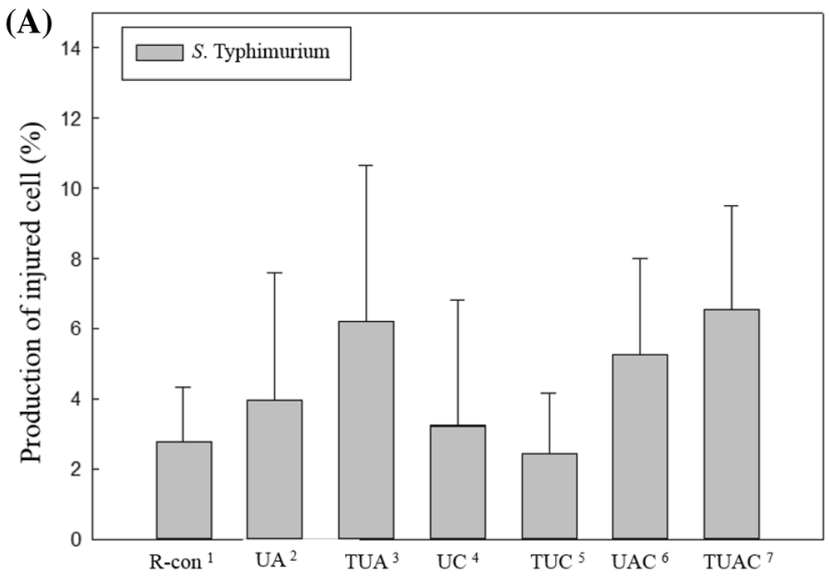

Fig. 3 Average number of injured cell of $S$. Typhimurium (A) and E. coli $\mathrm{O} 157: \mathrm{H} 7$ (B) produced by UV-A, UV-C, and $\mathrm{TiO}_{2}$ coating during treatment. Mean \pm standard deviation obtained in two experiments, one of two experiments in duplicated $(n=3)$. ${ }^{1} \mathrm{R}$-con means control group that was treated using only a roaster machine. ${ }^{2} \mathrm{UA}$ means a group that was treated by UV-A alone. ${ }^{3}$ TUA means a group

inactivation effect of UV combined with $\mathrm{TiO}_{2}$ coating was increased compared with UV alone treatment.

\section{Production of injured cell by UV-A, UV-C irradiation and $\mathrm{TiO}_{2}$ coating}

The number of injured $S$. Typhimurium and E. coli O157:H7 cells on BPP after treatment with UV-A, UV-C and $\mathrm{TiO}_{2}$ coatings is shown in Fig. 3. In Fig. 3(A) is the number of injured $S$. Typhimurium, and (B) is the number of injured E. coli O157:H7. Immediately after inoculation, $4.70 \%$ and $2.46 \%$ of the $S$. Typhimurium and E. coli

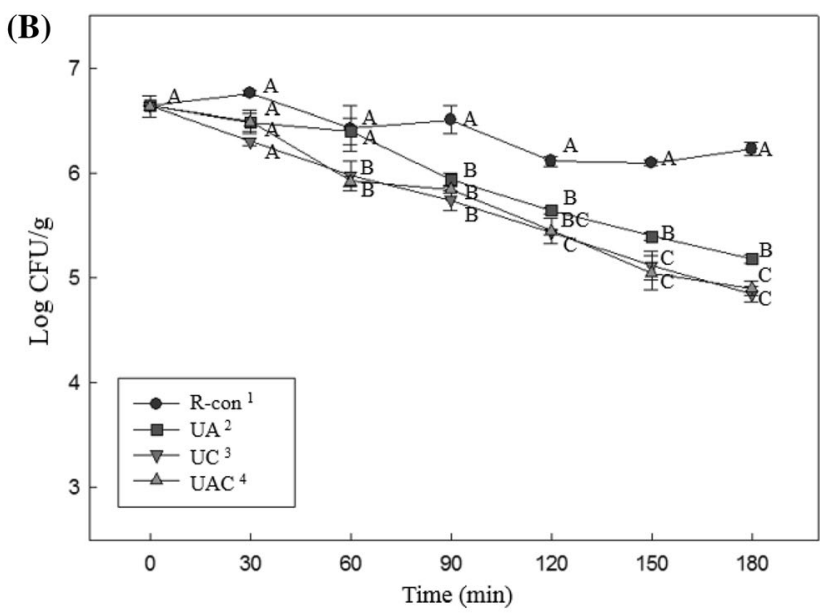

differences $(p<0.05)$ among treatments for each time. ${ }^{1} \mathrm{R}$-con means control group that was treated using only a roaster machine. ${ }^{2} \mathrm{UA}$ means a group that was treated by UV-A alone. ${ }^{3} \mathrm{UC}$ means a group that was treated by UV-C alone. ${ }^{4} \mathrm{UAC}$ means a group that was treated by UV-A and UV-C simultaneously

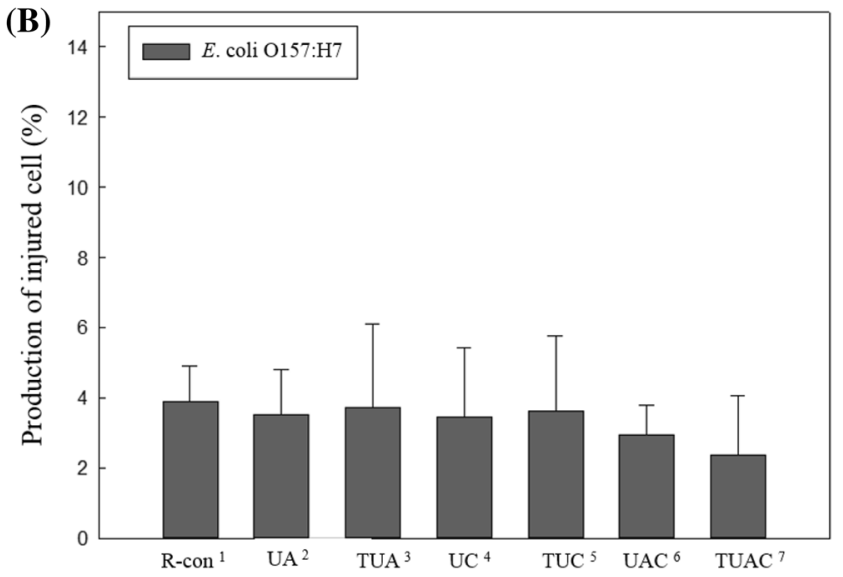

that was treated by $\mathrm{UV}-\mathrm{C}$ and $\mathrm{TiO}_{2} .{ }^{4} \mathrm{UC}$ means a group that was treated by UV-C alone. ${ }^{5}$ TUC means a group that was treated by UV$\mathrm{C}$ and $\mathrm{TiO}_{2} .{ }^{6} \mathrm{UAC}$ means a group that was treated by UV-A and UV$\mathrm{C}$ simultaneously. ${ }^{7}$ TUAC means a group that was simultaneously treated by UV-A, UV-C, and $\mathrm{TiO}_{2}$

O157:H7 cells were injured, respectively. On average, $S$. Typhimurium and E. coli $\mathrm{O} 157: \mathrm{H} 7$ resulted in $2.77 \%$ and $3.89 \%$ injured cells, respectively, when the samples were continuously mixed using the roaster machine without any treatment (R-con).

UA and TUA produced an average of $3.95 \%$ and $6.20 \%$ injured cells, respectively, for $S$. Typhimurium on BPP. In the pepper powder treated with UC and TUC, the average number of injured $S$. Typhimurium was $3.24 \%$ and $2.43 \%$. In the UAC- and TUAC-treated BPP, there was an average of $5.26 \%$ and $6.55 \%$ of injured $S$. Typhimurium cells. In the pepper treated with $\mathrm{UA}, \mathrm{UC}$, and UAC, the average 
number of injured E. coli $\mathrm{O} 157: \mathrm{H} 7$ was $3.52 \%, 3.45 \%$, and $2.95 \%$, respectively. When treated with TUA, TUC, and TUAC, $3.74 \%, 3.63 \%$, and $2.38 \%$ of $E$. coli $\mathrm{O} 157: \mathrm{H} 7$ were injured on average.

All treatments except for the TUC treatment formed injured cells of $S$. Typhimurium more than R-con on average. On the other hand, the injured E. coli O157:H7 produced by UA, TUA, UC, TUC, UAC, and TUAC was on average less than that produced by R-con. However, on both $S$. Typhimurium and E. coli $\mathrm{O} 157: \mathrm{H} 7$, there was no significant $(p>0.05)$ difference between productions of the injured cells depending on the treatments. This result shows that all treatments including UV-A, UV-C and $\mathrm{TiO}_{2}$ coating do not affect production of the injured cell on BPP.

\section{Moisture changes of BPP during UV-A and UV-C irradiation combined with $\mathrm{TiO}_{2}$ coating}

The changes in the moisture content of BPP depending on the length of treatments using UV-A, UV-C, and $\mathrm{TiO}_{2}$ coatings are shown in Fig. 4. The initial moisture content of the pepper powder inoculated with $S$. Typhimurium and E. coli $\mathrm{O} 157: \mathrm{H} 7$ was $12.90 \pm 0.08 \%$. The moisture content of BPP treated by R-con for 180 min decreased by $2.61 \%$.

When UA and TUA were applied for $180 \mathrm{~min}$, the moisture content of BPP decreased by $3.81 \%$ and $3.69 \%$, respectively. UC and TUC decreased the moisture content of BPP by $3.20 \%$ and $3.11 \%$, respectively, for $180 \mathrm{~min}$.
The moisture content of BPP treated with UAC and TUAC for $180 \mathrm{~min}$ decreased by $3.66 \%$ and $3.60 \%$, respectively. The moisture content of BPP treated by UA was significantly $(p<0.05)$ lower than that of R-con after $60 \mathrm{~min}$, and TUA significantly $(p<0.05)$ decreased the moisture content to below that of R-con after $90 \mathrm{~min}$. UC and TUC were significantly $(p<0.05)$ different from R-con after 90 min. Compared with R-con, UAC and TUAC had significantly $(p<0.05)$ lower moisture content after $30 \mathrm{~min}$. UA, TUA, UC, TUC, UAC, and TUAC treatments for $180 \mathrm{~min}$ reduced the moisture content by $1.21 \%, 1.09 \%$, $0.59 \%, 0.50 \%, 1.06 \%$, and $1.00 \%$, respectively.

The UC and TUC treatments for $180 \mathrm{~min}$ had significantly $(p<0.05)$ fewer differences with $\mathrm{R}$-con, compared with other treatments. UCA- and TUCA-treated BPP had higher moisture content than UA- and TUA-treated BPP. These results show that UV-C is more effective than UV-A in maintaining the moisture content of BPP. In addition, it was confirmed that the treatment combined with $\mathrm{TiO}_{2}$ coating kept a higher moisture content than the treatment without $\mathrm{TiO}_{2}$ coating. These results indicate that $\mathrm{TiO}_{2}$ coating helps preserve the moisture content of BPP.

\section{Color changes of BPP during UV-A and UV-C irradiation combined with $\mathrm{TiO}_{2}$ coating}

Table 1 shows the effects of UV-A and UV-C treatments combined with $\mathrm{TiO}_{2}$ coating on the color of BPP. The $\mathrm{L}^{*}$,

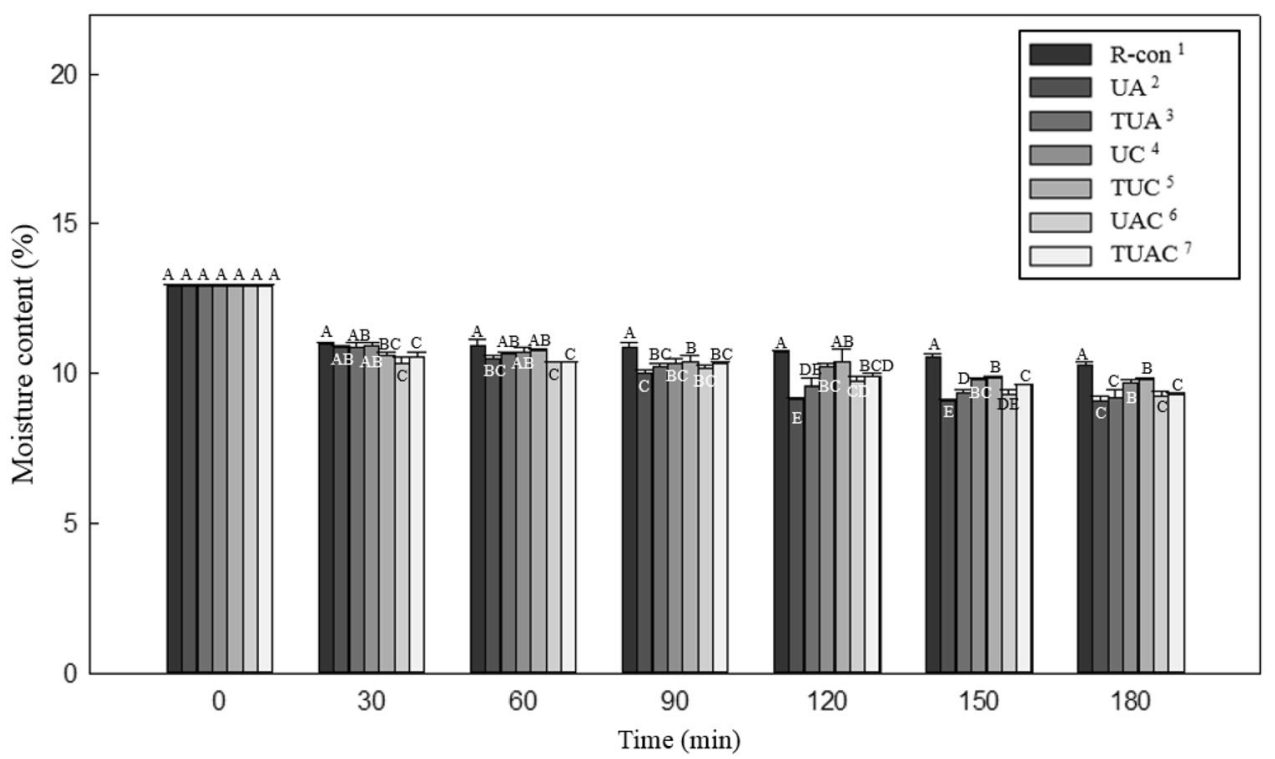

Fig. 4 Change of moisture content by UV-A, UV-C, and $\mathrm{TiO}_{2}$ coating on black pepper powder according to treatment time. Mean \pm standard deviation obtained in two experiments, one of two experiments in duplicated $(\mathrm{n}=3)$. Different capital letters indicate significant differences $(p<0.05)$ among treatments for each time. ${ }^{1} \mathrm{R}$-con means control group that was treated using only a roaster machine. ${ }^{2} \mathrm{UA}$ means a group that was treated by UV-A alone. ${ }^{3} \mathrm{TUA}$ means a group that was treated by UV-C and $\mathrm{TiO}_{2} .{ }^{4} \mathrm{UC}$ means a group that was treated by UV-C alone. ${ }^{5} \mathrm{TUC}$ means a group that was treated by UV-C and $\mathrm{TiO}_{2} .{ }^{6} \mathrm{UAC}$ means a group that was treated by UV-A and UV-C simultaneously. ${ }^{7}$ TUAC means a group that was simultaneously treated by UV-A, UV-C, and $\mathrm{TiO}_{2}$ 


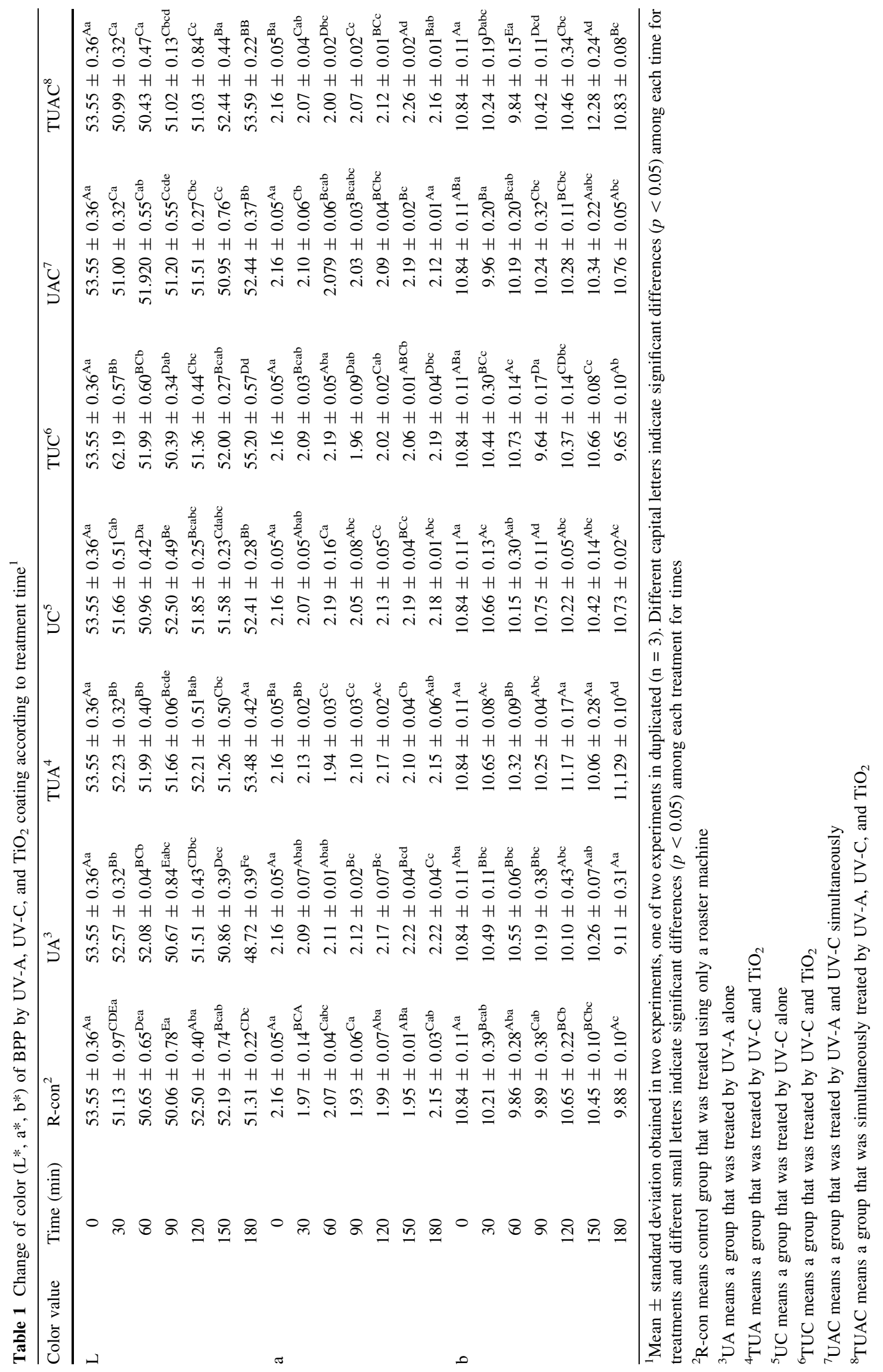


$\mathrm{a}^{*}$, and $\mathrm{b}^{*}$ values of untreated BPP were $53.55 \pm 0.36$, $2.16 \pm 0.05$, and $10.84 \pm 0.11$, respectively. In the case of R-con, $\mathrm{L}^{*}, \mathrm{a}^{*}$, and $\mathrm{b}^{*}$ values both significantly $(p<0.05)$ decreased and increased during treatment. The $\mathrm{L}^{*}, \mathrm{a}^{*}$, and $\mathrm{b}^{*}$ values of BPP increased or decreased by $3.49,0.22$, and 0.96 , respectively. However, because there is no significant $(p>0.05)$ trend depending on treatment time or treatment group, the change of color values by R-con is considered to be within the standard deviation between the samples.

When UA treatment was performed for $180 \mathrm{~min}$, the $\mathrm{L}^{*}$ value and the $b^{*}$ value decreased by 4.83 and 1.73 , respectively, which were significantly $(p<0.05)$ different from those of $\mathrm{R}$-con. This results indicated that the brightness of BPP is decreased, and the degree of blue of the pepper powder is increased by treatment. After TUC, the BPP was bluer than the R-con pepper powder at 90 and $180 \mathrm{~min}$. The blue color of BPP treated by TUAC increased at $30 \mathrm{~min}$ but decreased again after $60 \mathrm{~min}$. During the treatment, the blue color of BPP seemed to be increased by TUC and TUAC. However, since the value increased and decreased irregularly, it remains unclear whether the color of BPP is affected by TUC and TUAC. Therefore, we concluded that all treatments except UA did not affect the color of BPP. The combined treatment of UV-A, UV-C, and $\mathrm{TiO}_{2}$ coating was considered to be suitable for BPP as a treatment to inactivate food poisoning bacteria.

Ishibashi proved that $\cdot \mathrm{O}_{2}$ is generated in air and $\mathrm{TIO}_{2}$ interface by UV light using chemiluminescence method with high sensitivity (Ishibashi et al., 2000). This study tried to inactivate pathogens by directly contacting the black pepper powder inoculated pathogens with $\mathrm{TIO}_{2}$ coated on the roaster machine during UV irradiation. The treatments were used alone or combined to confirm increasing inactivation effects. Combined treatment of UVA and UV-C was effective for inactivating $S$. Typhimurium. The $\mathrm{TiO}_{2}$ coating increased the inactivation effect of UV-A and UV-C against $S$. Typhimurium and E. coli O157:H7. There was no significant $(p>0.05)$ difference between productions of the injured $S$. Typhimurium and E. coli $\mathrm{O} 157: \mathrm{H} 7$ depending on the treatments. UV-A, UV$\mathrm{C}$ and $\mathrm{TiO}_{2}$ coating do not affect production of the injured cell on BPP. The moisture content of BPP was decreased more by UV-A than by UV-C. UV-A treatment alone decreased the brightness and increased the degree of blue on BPP for $180 \mathrm{~min}$, but the other treatments did not affect the color of the BPP. Therefore, the combined treatment of UV-A, UV-C, and $\mathrm{TiO}_{2}$ coating maintains the quality of BPP and can be used effectively to sterilize BPP without heating.

Acknowledgements This work was supported by Korea Institute of Planning and Evaluation for Technology in Food, Agriculture,
Forestry (IPET) through High Value-added Food Technology Development Program, funded by Ministry of Agriculture, Food and Rural Affairs (MAFRA) (Grant Number 317030).

\section{References}

Alley M, Connolly J, Fenwick S, Mackereth G, Leyland M, Rogers L, Haycock M, Nicol C, Reed C. An epidemic of salmonellosis caused by Salmonella Typhimurium DT160 in wild birds and humans in New Zealand. N. Z. Vet. J. 50: 170-176 (2002)

Alrousan DM, Dunlop PS, McMurray TA, Byrne JA. Photocatalytic inactivation of $E$. coli in surface water using immobilised nanoparticle $\mathrm{TiO}_{2}$ films. Water Res. 43: 47-54 (2009)

Besser RE, Lett SM, Weber JT, Doyle MP, Barrett TJ, Wells JG, Griffin PM. An outbreak of diarrhea and hemolytic uremic syndrome from Escherichia coli O157:H7 in fresh-pressed apple cider. JAMA Netw. Open 269: 2217-2220 (1993)

Bintsis T, Litopoulou-Tzanetaki E, Robinson RK. Existing and potential applications of ultraviolet light in the food industry-a critical review. J. Sci. Food Agric. 80: 637-645 (2000)

Blake DM, Maness PC, Huang Z, Wolfrum EJ, Huang J, Jacoby WA. Application of the photocatalytic chemistry of titanium dioxide to disinfection and the killing of cancer cells. Sep. Purif. Methods 28: 1-50 (1999)

Chawengkijwanich C, Hayata Y. Development of $\mathrm{TiO}_{2}$ powdercoated food packaging film and its ability to inactivate Escherichia coli in vitro and in actual tests. Int. J. Food Microbiol. 123: 288-292 (2008)

Chevremont AC, Farnet AM, Coulomb B, Boudenne JL. Effect of coupled UV-A and UV-C LEDs on both microbiological and chemical pollution of urban wastewaters. Sci. Total Environ. 426: 304-310 (2012)

De Boer E, Spiegelenberg W, Janssen F. Microbiology of spices and herbs. Antonie Van Leeuwenhoek 51: 435-438 (1985)

Foster HA, Ditta IB, Varghese S, Steele A. Photocatalytic disinfection using titanium dioxide: spectrum and mechanism of antimicrobial activity. Appl. Microbiol. Biotechnol. 90: 1847-1868 (2011)

Gayán E, Monfort S, Álvarez I, Condón S. UV-C inactivation of Escherichia coli at different temperatures. Innov. Food Sci. Emerg. Technol. 12: 531-541 (2011)

Guerrero Beltr n J, Barbosa C novas G. Advantages and limitations on processing foods by UV light. Int. J. Food Sci. Technol. 10: 137-147 (2004)

Ishibashi KI, Fujishima A, Watanabe T, Hashimoto K. Generation and deactivation processes of superoxide formed on $\mathrm{TiO}_{2}$ film illuminated by very weak UV light in air or water. J. Phys. Chem. B 104: 4934-4938 (2000)

Islam M, Morgan J, Doyle MP, Phatak SC, Millner P, Jiang X. Fate of Salmonella enterica serovar Typhimurium on carrots and radishes grown in fields treated with contaminated manure composts or irrigation water. Appl. Environ. Microbiol. 70: 2497-2502 (2004)

Julian E, Macdonald K, Marsden-Haug N, Bonavolante R, Otero S, Nosari J, Austin C, Stein Dv, Garvey A, Kline G. Salmonella Montevideo infections associated with salami products made with contaminated imported black and red pepper-United States, July 2009-April 2010. MMWR Morb. Mortal. Wkly. Rep. 59: 1647-1650 (2010)

Kang DH, Siragusa G. Agar underlay method for recovery of sublethally heat-injured bacteria. Appl. Environ. Microbiol. 65: 5334-5337 (1999)

Knorr D, Froehling A, Jaeger H, Reineke K, Schlueter O, Schoessler K. Emerging technologies in food processing. Annu. Rev. Food Sci. Technol. 2: 203-235 (2011) 
Lee S-Y, Kang DH. Suitability of overlay method for recovery of heat-injured Listeria monocytogenes and Salmonella Typhimurium. Food Sci. Biotechnol. 10: 323-326 (2001)

Maness PC, Smolinski S, Blake DM, Huang Z, Wolfrum EJ, Jacoby WA. Bactericidal activity of photocatalytic $\mathrm{TiO}_{2}$ reaction: toward an understanding of its killing mechanism. Appl. Environ. Microbiol. 65: 4094-4098 (1999)

McKee L. Microbial contamination of spices and herbs: a review. LWT Food Sci. Technol. 28: 1-11 (1995)

Ojha KS, Kerry JP, Duffy G, Beresford T, Tiwari BK. Technological advances for enhancing quality and safety of fermented meat products. Trends Food Sci. Technol. 44: 105-116 (2015)

Oppezzo OJ, Pizarro RA. Sublethal effects of ultraviolet A radiation on Enterobacter cloacae. J. Photochem. Photobiol. B Biol. 62: 158-165 (2001)

Peter K. Handbook of herbs and spices. Woodhead publishing. England. p. 568 (2006)
Tarr PI. Escherichia coli O157:H7: clinical, diagnostic, and epidemiological aspects of human infection. Clin. Infect. Dis. 20: 1-8 (1995)

Ukuku DO, Geveke DJ. A combined treatment of UV-light and radio frequency electric field for the inactivation of Escherichia coli K-12 in apple juice. Int. J. Food Microbiol. 138: 50-55 (2010)

Yemmireddy VK, Hung YC. Effect of binder on the physical stability and bactericidal property of titanium dioxide $\left(\mathrm{TiO}_{2}\right)$ nanocoatings on food contact surfaces. Food Control 57: 82-88 (2015)

Zweifel C, Stephan R. Spices and herbs as source of Salmonellarelated foodborne diseases. Food Res. Int. 45: 765-769 (2012)

Publisher's Note Springer Nature remains neutral with regard to jurisdictional claims in published maps and institutional affiliations. 